\title{
Weight, Sodium and Potassium Intake Perceptions among University Students in Barbados: Results from a Cardiovascular Health Perception Survey
}

\author{
KZ Wang ${ }^{1}$, D Cohall ${ }^{2}$, T Scantlebury-Manning ${ }^{3}$
}

\begin{abstract}
Objective: To evaluate undergraduates' student sodium and potassium intakes, their perceptions towards these parameters and their cardiovascular health at The University of the West Indies, Cave Hill Campus.

Methods: The study is a cross-sectional study with a self-administered on-line questionnaire which included a three-day semi-quantitative food frequency questionnaire. The variables measured were: sodium and potassium intakes, body mass index (BMI) and the students' perceptions of their health and dietary intake. The data analyses included: descriptive statistics, $\mathrm{t}$-tests and one-way analysis of variance (ANOVA) with Tukey post-hoc test with statistical significance at the $95 \%$ confidence level.

Results: One hundred and five students aged $24.3 \pm 7.9$ years participated with a response rate of $8.8 \%$. Ninety-three (89\%) of the participants were Afro-Caribbean. Dietary sodium (3446 $\pm 1889 \mathrm{mg} /$ daily) and potassium (2740 $\pm 1957 \mathrm{mg} /$ daily) were estimated. The students with under-estimated sodium and potassium intakes consumed significantly more compared to the students who over-estimated their intake $(\mathrm{p}<0.05)$. The participants who under-estimated their weights had higher BMI values. Thirty per cent of the sample also indicated that they were unaware if they were at risk of developing a cardiovascular disease.

Conclusions: There is excessive dietary sodium and suboptimal potassium intakes which are coupled with the students' poor health perceptions. The findings support the need for more robust studies which can support the establishment of interventions to decrease cardiovascular (CVD) behavioural risk factors among undergraduate students.
\end{abstract}

Keywords: Body mass index, dietary intakes, health perceptions, potassium, sodium

\section{Percepciones del Peso y de la Ingestión de Sodio y Potasio Entre Estudiantes Universitarios en Barbados: Resultados de una Encuesta de Percepción de Salud Cardiovascular \\ KZ Wang ${ }^{1}$, D Cohall ${ }^{2}$, T Scantlebury-Manning ${ }^{3}$}

\begin{abstract}
RESUMEN
Objetivo: Evaluar las ingestiones de sodio y potasio de los estudiantes de pregrado, sus percepciones hacia estos parámetros, y su salud cardiovascular en la Universidad de West Indies, campus Cave Hill.
\end{abstract}

From: ${ }^{1}$ School of Dietetics and Human Nutrition, McGill University, 21111 Lakeshore Road Ste-Anne-de-Bellevue, Quebec H9X 3V9, ${ }^{2}$ Faculty of Medical Sciences, The University of the West Indies, Cave Hill, St Michael, Barbados and ${ }^{3}$ Faculty of Science and Technology, The University of the West Indies Cave Hill, St Michael, Barbados.
Correspondence: Dr D Cohall, Faculty of Medical Sciences, The University of the West Indies, Cave Hill, St Michael, Barbados, Email:damian.cohall@cavehill.uwi.edu 
Métodos: Se trata de un estudio transversal con un cuestionario en línea autoadministrado que incluyó un cuestionario semicuantitativo de frecuencia alimentaria de tres días. Las variables medidas fueron: las ingestas de sodio y potasio, el indice de masa corporal (IMC) y la percepción de los estudiantes de su salud y su consumo dietético. Los análisis de datos incluyeron: estadísticas descriptivas, pruebas $\mathrm{t}$ y análisis de varianza unidireccional (ANOVA) con prueba post-hoc Tukey de valor estadístico a un nivel de confianza de $95 \%$.

Resultados: Ciento cinco estudiantes de $24.3 \pm 7.9$ años de edad participaron con una tasa de respuesta de $8.8 \%$. Noventa y tres (89\%) de los participantes eran afrocaribeños. Se hizo un cálculo estimado del sodio dietético (3446 $\pm 1889 \mathrm{mg} /$ diario) y el potasio $(2740 \pm 1957 \mathrm{mg} /$ diario). Los estudiantes que subestimaron sus ingestas de sodio y potasio consumieron significativamente más en comparación con los estudiantes que sobrestimaron su consumo (p < 0.05). Los participantes que subestimaron sus pesos tenían valores más altos de IMC. El 30\% de la muestra también indicó que no sabían si corrían el riesgo de desarrollar una enfermedad cardiovascular.

Conclusiones: Hay exceso de sodio en la dieta e ingestas de potasio subóptimas que se suma a las pobres percepciones de la salud por parte de los estudiantes. Los hallazgos apoyan la necesidad de estudios más robustos que puedan apoyar la puesta en práctica de intervenciones para disminuir los factores de riesgo conductuales cardiovasculares (ECV) entre los estudiantes de pregrado.

Palabras clave: Índice de masa corporal, ingestas dietéticas, percepciones de salud, potasio, sodio

\section{West Indian Med J 2017; 66 (6): 642}

\section{BACKGROUND}

Hypertension, a major risk factor for cardiovascular diseases, is usually described as having elevated blood pressure equivalent or greater than systolic blood pressure of $140 \mathrm{mmHg}$ and diastolic blood pressure of $90 \mathrm{mmHg}$, or taking medications for blood pressure (1). The relationship between the risk of developing hypertension and ethnicity has been of interest as multiple studies from Europe and the United States of America (USA) have reported a higher prevalence, and earlier onset of hypertension in Black individuals than Whites (2). This may be explained by influences of both genetic and environmental factors (3). The higher prevalence is coupled with a reported lower level of hypertension awareness in Black people (2).

In Barbados, where over $90 \%$ of its residents are of African descent, the issues of the residents' susceptibility to hypertension and "salt-sensitivity" should be of public health importance (4). In recent years, an on-going nutrition transition has been witnessed in Barbados, mainly characterized by the wide replacement of nutrient-dense foods with fast and processed foods. Experts believe that the nutrition transition has contributed to the rise of non-communicable diseases like hypertension in Barbados (5). Evidence from a number of large randomized controlled trials, point to a direct dose-response relationship between dietary sodium intake and blood pressure (6). The diet habitually consumed by Barbadians is suggested to be high, and likely well in excess of the Institute of Medicine's (IOM) sodium tolerable upper intake level of $2300 \mathrm{mg} /$ daily $(7,8)$. "Salt-sensitive" persons are defined as individuals whose blood pressures fluctuate with changes in their dietary sodium intake (9). Whereas in most healthy normotensive individuals, the changes in their dietary sodium consumption do not adversely affect their blood pressure since their renal sodium excretion can normally compensate for the change. Along with hypertension, several recent trials have shown that "salt-sensitivity" may also be more prevalent among Blacks (3).

On the other hand, dietary potassium is found to have a blood pressure lowering effect (10). Recent NHANES survey showed that the dietary intake of potassium among Americans in general, as well as the subgroup of African Americans seemed to be sub-optimal, compared with the adequate intake of level of $4700 \mathrm{mg}$ /daily (8). The major sources of potassium can be found in nutrient-dense foods like fruits, lean meat and low-fat dietary dairy products (11). 
The increase in processed foods engendered by the recent nutrition transition in Barbados leads to the postulation that a dietary intake pattern of excessive sodium and sub-optimal potassium may be observed among Barbadians (12). Taking into consideration that Afro-Caribbean Barbadians are likely to be at a high susceptibility of developing hypertension, understanding their perception regarding their current dietary habits and the associated risks of developing hypertension will be important to policy-makers to formulate necessary intervention strategies to this wide-spread health issue (13). Particularly given the likelihood of an earlier onset of hypertension among Blacks, focussing on a subgroup of young adults regarding their current nutritional habits and health perceptions would be important to pinpoint potential intervention strategies (2). Another advantage with earlier intervention with lifestyle modification would be prolonged health benefits.

Currently, no research has yet investigated the health perceptions of young adults in Barbados with regards to their sodium and potassium intakes and CVD risks. The undergraduate student body at the UWI Cave Hill is a good site for this, as the campus is widely regarded as the microcosm of the Barbadian society within the adult age group of 18 to 25 years. With this study, we explored this area of research interest.

\section{SUBJECTS AND METHODS}

The ethical considerations of this project were reviewed and approved by The University of West Indies/Ministry of Health Institutional Review Board.

\section{Participants and recruitment}

A total of 7319 undergraduate students were registered at the UWI's Cave Hill campus for the academic year 2014 to 2015 (14). The past internet-based studies done among college students from the USA have reported response rates in the range of $30 \%$ to $60 \%$, thus, for this study, the expected response rate was assumed to be around $50 \%(15-17)$. A sample of 1200 students were randomly selected to produce a projected representative sample size of 555 undergraduate students at $95 \%$ confidence level with a $4 \%$ confidence interval. A study invitation letter with a URL link to the survey questionnaire was sent to the students by enrolling them to an on-line course developed within the UWI's Moodle e-Learning system. Students accessed the questionnaire from their user specific access to the e-Learning system.
Survey questionnaire development, validation and administration

A questionnaire was developed and validated specifically for the purpose of this study after consulting numerous sources $(5,7,18,19)$. Established items from other food frequency questionnaire instruments were incorporated in the semi-quantitative food frequency questionnaire. The questionnaire was piloted among undergraduate students and modified to suit the population being tested. Food items that represent significant sources of sodium and potassium in the typical Barbadian diet were included in the questionnaire. Household measurement units like "scoop" and "glass" were used as the standard units of measurements (18). The administration of the survey questionnaire was done through Google Forms and facilitated by the Moodle e-Learning system. The survey instrument has 24 items with mainly multiple choice and dichotomous questions and included a semi-quantitative food frequency questionnaire that explores a three-day dietary intake of sodium and potassium rich foods. The semi-quantitative food frequency component included ten questions which were used to estimate the subject's daily dietary sodium and potassium intakes. The other questions addressed their perceptions of health and self-reported data on physical attributes were used to estimate their BMI. The questionnaire was administered over a seven-day period, as wide variations in internet-based survey responses have been reported (15).

\section{Statistical analyses}

The variables measured were: sodium and potassium intake, BMI and the subject's perceptions of health and dietary intake. The results of sodium and potassium intake were categorized into either "lower", "about", or "higher" than the dietary intake recommendations from IOM, $2.3 \mathrm{~g} / \mathrm{L}$ and $4.7 \mathrm{~g} / \mathrm{L}$ for sodium and potassium, respectively. The results were then compared with the participants' self-perception toward their sodium and potassium intake. The participants were marked as having either "under-estimated", "correctly estimated", or "over-estimated" their dietary sodium and potassium intakes. Their reported perception of BMI is compared to the computed BMI from reported weight and height in a similar fashion, where BMI of $<18.5$ is considered as underweight, between 18.5 and 24.9 is considered as normal weight, and between 25 and 29.9 is considered as overweight and $>30$ is regarded as obese as used in other studies done in Barbados (5). 
All the data were analysed using GraphPad Prism (Version 6, GraphPad Software, La Jolla, CA, USA). The statistical analyses used included: descriptive statistics (mean, SD, SEM, proportion), unpaired $t$-tests and oneway (ANOVA) with Tukey post-hoc test. Significance was determined at the $95 \%$ confidence level $(p<0.05)$.

\section{RESULTS}

In total, the preliminary results showed 105 out of the sample of 1200 undergraduate students who were randomly selected from the undergraduate student database $(\mathrm{n}=7319)$ responded to the survey during the course of its administration, yielding a response rate of $8.8 \%$.

Out of the 105 responses, $78 \%$ were from females $(\mathrm{n}=82)$ and $22 \%$ were from males $(\mathrm{n}=23)$, with a mean age of 24.3 years $(\mathrm{SD}=7.9)$. Eighty-nine per cent of the participants were Afro-Caribbean $(\mathrm{n}=$ 93). The results from the three-day dietary intake section of the questionnaire were computed to obtain the average daily sodium and potassium intakes for each participant. Table 1 provides a summary of participants' characteristics. The average sodium intake was estimated to be $3462 \mathrm{mg} /$ daily, with the major contributing dietary sources being bread, fried meat or fish, rice and peas, macaroni pie and pasta with sauce. On the other hand, the average potassium intake was estimated to be $2890 \mathrm{mg} /$ daily, which is well below the recommended amount of $4700 \mathrm{mg} /$ daily (8). The major sources of potassium included: fried fish, French fries, milk, fresh fruit, fresh vegetables and fruit juices.

Table 1: Participants' demographics on the dietary intake study $(\mathrm{n}=105)$.

\begin{tabular}{lc}
\hline Variable & Survey findings/ unit \\
\hline Number of participants $(\mathrm{n})$ & 105 \\
Afro-Caribbean & $89 \%$ \\
Resided in Barbados for $>10$ years & $81 \%$ \\
Mean age (years)* & $24.3 \pm 7.9$ \\
Mean body mass index $\left(\mathrm{kg} / \mathrm{m}^{2}\right)^{*}$ & $25.00 \pm 5.62$ \\
Three-day dietary Sodium $(\mathrm{mg})^{*}$ & $3446 \pm 1889$ \\
Three-day dietary Potassium $(\mathrm{mg})^{*}$ & $2740 \pm 1957$ \\
Current drinker & $5 \%$ \\
Current smoker & $3 \%$ \\
\hline
\end{tabular}

*Data are presented as mean $\pm \mathrm{SD}$; Current drinker $=1$ glass/day or more of alcohol.

The dietary intake results showed that $50(48 \%)$ of the students had under-estimated their dietary sodium intake. On the other hand, only $13(12 \%)$ of the students under-estimated their dietary potassium intake. The number of students who correctly estimated their sodium and potassium intakes were $35(33 \%)$ and 54 $(52 \%)$, respectively. While $20(19 \%)$ and $38(36 \%)$ of the students over-estimated their sodium and potassium intakes, respectively. Of those surveyed, $30 \%$ were not sure if they were at risk of hypertension.

The data analyses showed significantly less dietary sodium intake from the participants who had over-estimated their three-day dietary sodium intake, compared to those who had either under-estimated or correctly estimated their sodium intake. With regards to potassium, the analyses showed significant differences between the students who had under-estimated their potassium intake with those who had either correctly estimated or over-estimated their potassium intake. These results are presented in Figs. 1 and 2. All the data are presented as mean $\pm \mathrm{SD}$.

In terms of weight perception, $23(22 \%), 72(69 \%)$ and $10(9 \%)$ of the students had under-estimated, correctly estimated and over-estimated their weights, respectively. Table 2 provides detailed summaries regarding the participants' weights and the prevalence of their underestimation.

Table 2: The prevalence of weight underestimation among participants in the dietary intake study.

\begin{tabular}{lccc}
\hline BMI classification & n & $\begin{array}{c}\text { Weight under-estimation (n, \%) } \\
\text { n }\end{array}$ \\
\hline Underweight BMI group & 7 & 0 & 0 \\
Normal weight BMI group & 55 & 4 & $7 \%$ \\
Overweight BMI group & 21 & 4 & $19 \%$ \\
Obese BMI group & 22 & 15 & $68 \%$ \\
\hline
\end{tabular}

BMI: body mass index

The statistical analyses showed significantly higher average $\mathrm{BMI} \pm \mathrm{SD}$ among the participants who had under-estimated their weights $\left(30.26 \pm 5.78 \mathrm{~kg} / \mathrm{m}^{2}\right)$ compared to $23.74 \pm 4.82 \mathrm{~kg} / \mathrm{m}^{2}$ and $21.98 \pm 2.41 \mathrm{~kg} / \mathrm{m}^{2}$ for the correctly estimated and over-estimated groups $(p<0.0001)$. All the data in the figures are presented as mean \pm SD.

\section{DISCUSSION}

This study highlights the inadequacy of health perceptions among a sample of university students in Barbados. The students' responses indicated an average BMI of $25 \mathrm{~kg} / \mathrm{m}^{2}$, suggesting a trend tending towards overweight weight-status. The participants from the obese BMI group were observed to have the highest likelihood to underestimate their weights, which is consistent with other findings among university students in 21 countries 
globally (20). In total, about $30 \%$ of all the 105 students misinterpreted their weight-status. This relatively high proportion suggests the probable need for more educational programmes to address this knowledge deficit, as unhealthy weight status may lead to negative cardiovascular health consequences $(21,22)$.

The results from the three-day semi-quantitative food frequency questionnaire demonstrated that the students consumed inappropriate quantities of sodium and potassium from dietary sources on the consideration of the IOM's dietary sodium and potassium recommendations (8). The findings in this study showed that the average sodium intake was estimated to be above the IOM's recommendations. The main sources of dietary sodium

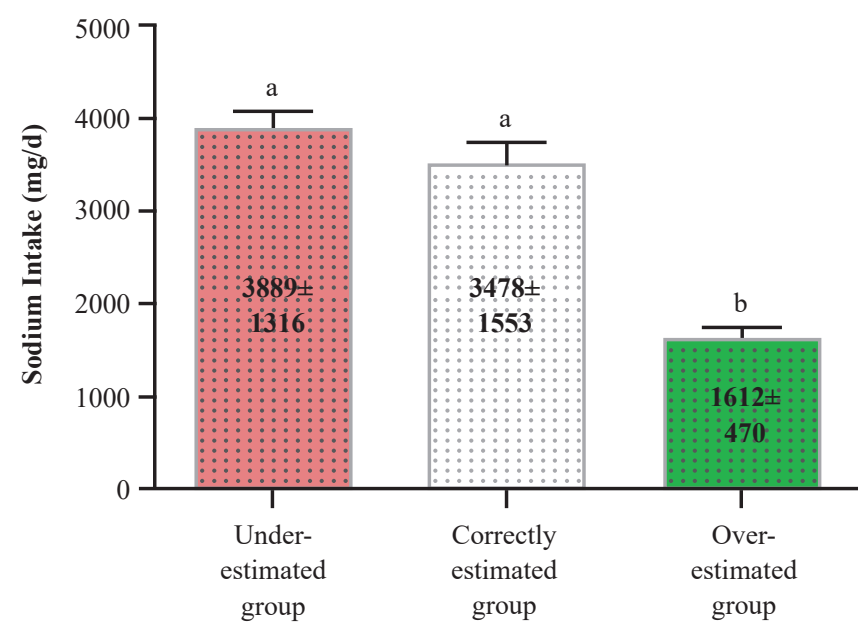

Fig. 1: Measured and estimated dietary sodium intake among the undergraduate students. Note that "a" and "b" in the figure indicate statistical differences between the under-estimated group and the other comparative groups at $p<0.0001$.

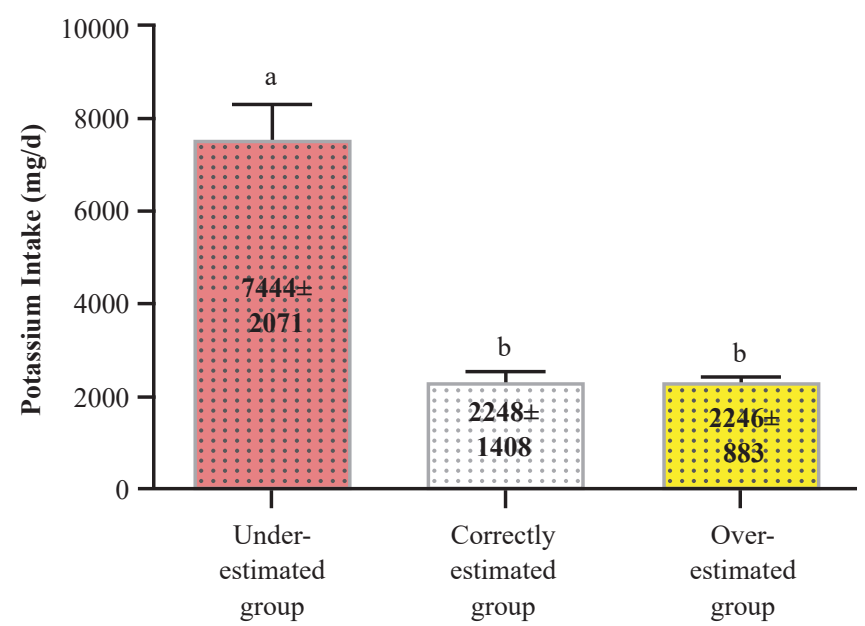

Fig. 2: Measured and estimated dietary potassium intake among the undergraduate students. Note that "a" and "b" in the figure indicate statistical differences between the under-estimated group and the other comparative groups at $p<0.0001$. agrees with the results from the Barbados Salt Intake Survey, where these sources have also been identified (7). On the other hand, the average potassium intake was estimated to be below the IOM's daily recommendation. No data regarding the dietary potassium intake level among the young adult Barbadian population have been reported. Evidence from a sample of normotensive Barbadian adults also points to the pattern of suboptimal dietary potassium consumption (23). The findings also highlight the possible need for interventions to augment dietary potassium intake in the Barbadian population.

In terms of dietary intake perceptions, only $35 \%$ of the sampled students correctly identified their dietary sodium intake, while about half $(48 \%)$ of the students under-estimated their sodium intake. Conversely, for potassium, the over-estimation appears to be more common than the under-estimation ( $36 \%$ vs $12 \%)$. Significantly lower sodium intake has been observed among participants who have over-estimated their sodium intake (1612 mg vs $3889 \mathrm{mg}, 3478 \mathrm{mg}$ ).

Whereas for potassium, the participants who have under-estimated their three-day potassium intake reported a significantly higher intake level (7444 mg/daily), compared to both the correctly estimated $(2248 \mathrm{mg} /$ daily) and the over-estimated (2246 mg/daily) groups. These results confirm the pattern of nutritional imbalance as depicted by the over-consumption of sodium and the sub-optimal consumption of potassium. This imbalance agrees with the observations in other parts of the world (8). This health risk is further heightened by participants from the obese BMI group having the

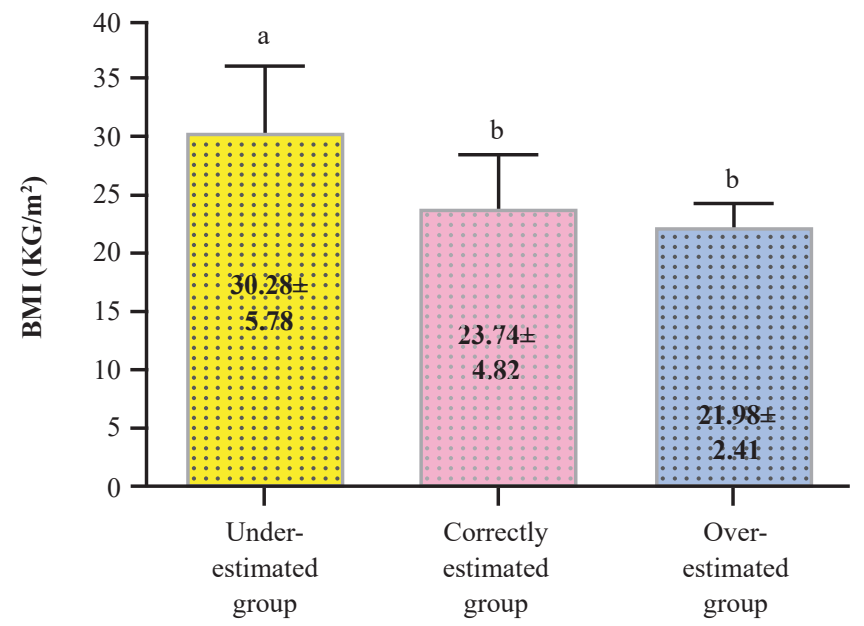

Fig. 3: Measured and estimated body mass index among the undergraduate students. Note that "a" and "b" in the figure indicate statistical differences between the under-estimated group and the other comparative groups at $p<0.0001$. 
highest likelihood to underestimate their weights. These results demonstrate a lack of understanding of CVD risks among the students regarding their weight, dietary sodium and potassium intakes, with those further away from the recommended dietary intake levels being more at risk of having misperceptions regarding their health. Especially taking the high uncertainty $(30 \%)$ regarding hypertension risk detected from this study into consideration, educational programmes focussing on their CVDs and their associated risk factors, and potential lifestyle modifications will likely be beneficial to improve the students' understanding of their dietary sodium and potassium intakes and their health implications.

It is evident that there is nutritional inadequacy in the typical diets in Barbados, where dishes high in sodium, fat and carbohydrates are commonly consumed (5). Cooking methods commonly practised in Barbados may promote this nutritional imbalance. For instance, the results of the three-day semi-quantitative food frequency questionnaire identified potatoes by means of French fries as a major source of potassium among the students. Instead of frying, cooking methods like mashing or boiling may be considered as the healthier alternatives.

The low response rate in the study may be explained by the fact that the timing of the study coincided with the university's final examination period which was circumstantial and coincided with the data collection period of the study; thus, the students might have been occupied otherwise. Otherwise, the poor response rate may also reflect the indifference among undergraduates towards their health and dietary practices. Regarding the survey's length, Pealer et al, reported one to 24 days of response time for a group of college students from Florida to complete a health survey questionnaire, with the mean response time being 9.75 days $[\mathrm{SD}=7.12$ ] (15). The seven days, during which they had to respond to this study's questionnaire might be inadequate.

Another limitation of this survey is the reliance on self-reporting, as the questionnaire was self-administered via Google Forms. In regards to weight reporting, most studies conducted in the adult population have found that self-reporting may lead to under-estimation of weight and to over-estimation of height, with a combined overall effect of under-estimating BMI (24). In terms of diet, the self-reporting of three-day dietary recall might be associated with inaccuracies like recall bias (25).

This study is the first that assesses young adults' health perceptions in Barbados and shows the inadequate perceptions of weight, sodium and potassium intakes among a sample of undergraduate students in Barbados. Further results with a representative sample of the undergraduate population will be useful to direct appropriate interventional programmes in an effort to decrease the behavioural risk factors associated with cardiovascular disease, primarily hypertension and its sequela. Educational-based interventions at the tertiary level may be a consequence if the results of future population-based studies reflect similar findings.

\section{REFERENCES}

1. Giles TD, Materson BJ, Cohn JN, Kostis JB. Definition and classification of hypertension: an update. J Clin Hypertens (Greenwich) 2009; 11: $611-14$.

2. Brown MJ. Hypertension and ethnic group. BMJ 2006; 332: 833-36.

3. Richardson SI, Freedman BI, Ellison DH, Rodriguez CJ. Salt sensitivity: a review with a focus on non-Hispanic blacks and Hispanics. J Am Soc Hypertens 2013; 7: 170-79.

4. Barbados Statistical Service. Population and Housing Census. Brigetown, Barbados: Barbados Statistical Service; 2010.[rev. 2015; cited 21 June 2015]. Available from: http://www.barstats.gov.bb/files/ documents/PHC_2010_Census_Volume_1.pdf.

5. Sharma S, Cao X, Harris R, Hennis AJ, Wu SY, Leske MC, Barbados National Cancer Study Group. Barbados National Cancer Study G. Assessing dietary patterns in Barbados highlights the need for nutritional intervention to reduce risk of chronic disease. J Hum Nutr Diet 2008; 21: $150-58$.

6. Sacks FM, Svetkey LP, Vollmer WM, Appel LJ, Bray GA; DASHSodium Collaborative Research Group et al. Effects on Blood Pressure of Reduced Dietary Sodium and the Dietary Approaches to Stop Hypertension (DASH) Diet. New Engl J Med 2001; 344: 3-10.

7. Sharma S, Oberdorff BL, Hopping BN, Rose A MC, Howitt C, Harris R et al. Identifying dietary sources of sodium to inform a salt intervention trial for Barbados: Results from the Barbados Salt Intake Survey. Faseb J 2011; 25.

8. Cogswell ME, Zhang Z, Carriquiry AL, Gunn JP, Kuklina EV, Saydah $\mathrm{SH}$ et al. Sodium and potassium intakes among US adults: NHANES 2003-2008. Am J Clin Nutr 2012; 96: 647-57.

9. Krauss RM, Eckel RH, Howard B, Appel LJ, Daniels SR, Deckelbaum RJ et al. AHA Dietary Guidelines: revision 2000: A statement for healthcare professionals from the Nutrition Committee of the American Heart Association. Stroke 2000; 31: 2751-766.

10. Langford HG. Sodium-potassium interaction in hypertension and hypertensive cardiovascular disease. Hypertension 1991; 17: I155-57.

11. Morris RC Jr, Sebastian A, Forman A, Tanaka M, Schmidlin O. Normotensive salt sensitivity: effects of race and dietary potassium. Hypertension 1999; 33: 18-23.

12. Sheehy T, Sharma S. The nutrition transition in Barbados: trends in macronutrient supply from 1961 to 2003. Br J Nutr 2010; 104: 1222-229.

13. Jones DW, Hall JE. Racial and ethnic differences in blood pressure: biology and sociolo- gy. Circulation 2006; 114: 2757-759.

14. The University of the West indies. University of West Indies Cave Hill Campus Statistics 2013-2014. St Michael, Barbados: The University of the West indies; 2014.

15. Pealer LN, Weiler RM, Pigg RM Jr, Miller D, Dorman SM. The feasibility of a web-based surveillance system to collect health risk behavior data from college students. Health Educ Behav 2001; 28: 547-59.

16. Shih TH, Fan XT. Comparing response rates in e-mail and paper surveys: A meta-analysis. Educ Res Rev 2009; 4: 26-40.

17. Stones A, Perry D. Survey questionnaire data on panic attacks gathered using the World Wide Web. Depress Anxiety 1997; 6: 86-87.

18. Sharma S, Cao X, Harris R, Hennis AJ, Leske MC, Wu SY; Barbados National Cancer Study Group. Barbados National Cancer Study 
G. Dietary intake and development of a quantitative food-frequency questionnaire for the Barbados National Cancer Study. Public Health Nutr 2007; 10: 464-70.

19. United States Department of Agriculture. USDA National Nutrient Database 2011. Betsville, Maryland, US: United States Department of Agriculture; 2011. [rev. 07 Dec 2011; cited 2206 2015] Available from: http://ndb.nal.usda.gov/.

20. Peltzer K, Pengpid S. Underestimation of weight and its associated factors in overweight and obese university students from 21 low, middle and emerging economy countries. Obes Res Clin Pract 2014.

21. Eisenberg ME, Neumark-Sztainer D, Story M, Perry C. The role of social norms and friends' influences on unhealthy weight-control behaviors among adolescent girls. Soc Sci Med 2005; 60: 1165-73.
22. Must A, Strauss RS. Risks and consequences of childhood and adolescent obesity. Int J Obesity 1999; 23: S2-S11.

23. Cohall DH, Scantlebury-Manning T, Rafie C, James S, Hall K. Dietary potassium intake and renal handling, and their impact on the cardiovascular health of normotensive Afro-Caribbeans. West Indian Med J 2014; 63: 13-19.

24. Yannakoulia M, Panagiotakos DB, Pitsavos C, Stefanadis C. Correlates of BMI misreporting among apparently healthy individuals: the ATTICA study. Obesity (Silver Spring) 2006; 14: 894-901.

25. Schoeller DA. Limitations in the assessment of dietary energy intake by self-report. Metabolism 1995; 44: 18-22. 